\title{
Laboratory and intra-oral tests of the degradation of elastic chains
}

\author{
R. Kuster, B. Ingervall and W. Bürgin \\ Orthodontic Clinic, University of Bern, Switzerland
}

SUMmaRY Two brands of elastic chain, Alastic (Unitek Co.) and Power Chain II (Ormco Co.), were tested for force development in laboratory and intra-oral experiments.

During the laboratory test, the chains were extended to 180 and 215 per cent of their original passive length and the force exerted at this length was measured at the start and after 15 minutes, 2, 8 and 24 hours, 3 days and 1, 2, 3 and 4 weeks of continuous extension. The two brands behaved similarly. After 4 weeks, they had lost 25-30 per cent of their initial force. The decrease of the force value was greatest in the beginning of the test period, with a decline of 6-11 per cent during the first 15 minutes and 10-16 per cent during the first 2 hours.

The intra-oral tests were performed in 10-25 subjects, who wore the elastic chains continuously for up to 4 weeks. The chains were extended up to 200 per cent of their original passive length. In one test, the force development was measured at the start and after 8 and 24 hours, 5 days and 1, 2, 3 and 4 weeks. In two other tests the force was measured after 1 day and 4 weeks, respectively.

The two brands behaved similarly. The decline of the force value during intra-oral use was greater than in the laboratory tests. After 4 weeks, the force was only 43-52 per cent of the original value. The decline was greatest in the initial phase after insertion; after 8 hours the force had declined by $28-34$ per cent. Thus, an initial force of $300 \mathrm{~g}$ was reduced to $200 \mathrm{~g}$ after 8 hours and to less than $150 \mathrm{~g}$ after 4 weeks: in no specimen was the force after 4 weeks less than $100 \mathrm{~g}$.

\section{Introduction}

Elastomeric elements are a common source of force for orthodontic tooth movement. The elements may be either rubber or polyurethanebased polymers. This paper deals with the latter type. Several studies have concerned themselves with the rate and amount of force degradation which these materials are known to undergo when continuously extended (Andreasen and Bishara, 1970; Bishara and Andreasen, 1970). It has been shown that the environment (air, fluid or intra-oral) in which the test specimens are kept during the test plays a role (Wong, 1976; Ash and Nikolai, 1978; Persson et al., 1983). Furthermore, the degree of extension and the rate of the initial extension have been studied for their influence on the force decay during prolonged periods of extension (Hershey and Reynolds, 1975; Kovatch et al., 1976). Prestretching of the elastic element has been shown to result in more constant force delivery due to the plastic deformation obtained before use (Brantley et al., 1979; Young and Sandrik, 1979; Hofmann and Miethke, 1981).

Most of the studies concerning the force degradation of elastomeric elements have been performed in vitro. During clinical use of such elements, however, factors that are not simulated in the in vitro studies add to the influence on the elastic element. Such factors may be chemical, from the saliva, food or oral hygiene products, thermal, due to the ingestion of hot and cold foods, and mechanical, due to mastication and oral hygiene procedures. These factors probably change the properties of the elastomeric components in a way that cannot be simulated in in vitro experiments. That this happens is suggested in one in vivo study. Thus, Ash and Nikolai (1978) found greater force relaxation of elastic chains after one week in the true oral environment than after waterbath simulation. When 
testing in air and in the mouth was compared, the force degradation was already shown to be greater in the mouth during the first day. In contrast to these findings, Howard and Nikolai (1979), comparing tests of a polymeric thread in air at room temperature and in vivo, did not find a greater force loss in the in vivo test until after six weeks. Some factors in intra-oral environment may not be deleterious to the force development of the elastic element. Thus, De Genova et al. (1985), in a recently reported laboratory study, found less force degradation of polyurethane-based elastic chains that had been subjected to thermal cycling than of those that had been kept at a constant temperature.

To our knowledge, the study by Ash and Nikolai (1978) is the only one reporting the behaviour of polyurethane elastomeric chains during actual use in the mouth and their findings differ from those obtained under laboratory conditions. Chains of polyurethane material have been widely used for intra-arch tooth movement. It was therefore felt to be of value to test the force development of such chains in vivo further in view of the probable difference between the actual oral environment and the simulated situation in the laboratory tests hitherto done.

\section{Material and methods}

Two brands of elastic chain were tested, Alastic $\mathrm{CI}$, grey type, from Unitek Co. and Power Chain II from Ormco Co. Four types of tests were performed:

(1) laboratory tests;

(2) a 4-week test in the oral cavity with periodic force measurements during the four-week period;

(3) a 24-hour test in the oral cavity and

(4) a 4-week test in the oral cavity.

In all tests the original length of the elastic chain and its length after use were measured in the passive state with a sliding caliper to 0.1 $\mathrm{mm}$. The force exerted by the elastic chain at the certain length was measured with an instrument of the type described by Persson et al. (1983). The instrument consists of a force gauge (Correx, Haag-Streit, Bern, Switzerland) graduated in grams and in newtons from 50 to $500 \mathrm{~g}$. The force gauge was mounted together with a ruler (Fig. 1) so that the force exerted by

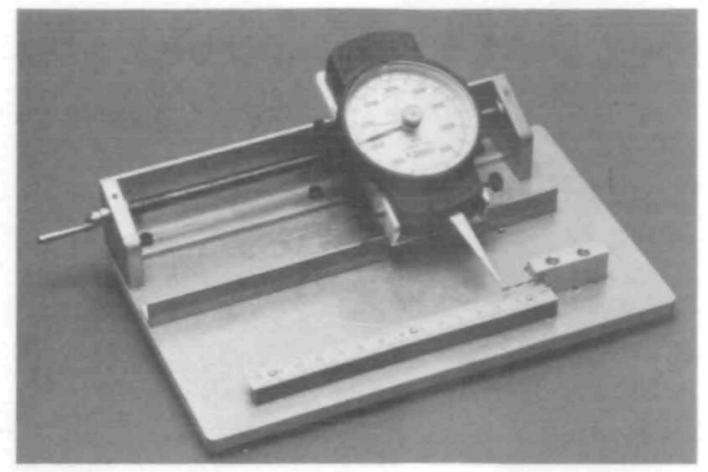

Figure 1 Force gauge and adjustable stand for the measurement of the force exerted by the elastic chain at variable lengths.

the elastic at a given length could be recorded. It was possible to extend the elastic chain gradually to the desired length (read to $0.5 \mathrm{~mm}$ ) and then on the measuring gauge read the force exerted.

The laboratory test (test 1) was performed with two lengths of extension of the chain (21 $\mathrm{mm}$ and $25 \mathrm{~mm}$ ). For both these extensions, the length of 4 rings (of both brands) was used. An unused chain of four rings of the Unitek brand had in the passive state a length of $11.6 \mathrm{~mm}$ and a chain of the Ormco brand had a length of 11.5 $\mathrm{mm}$. The extension of the Unitek brand was therefore 181 per cent of the original passive length at the $21 \mathrm{~mm}$ distance and 216 per cent at the $25 \mathrm{~mm}$ distance. The corresponding values for the Ormco brand were 183 per cent and 217 per cent. Ten specimens of each brand were tested and the force exerted at an extension distance of $21 \mathrm{~mm}$ and $25 \mathrm{~mm}$, respectively, was measured at the start (10 seconds after stretching) and after 15 minutes, 2 hours, 8 hours, 24 hours, 3 days and 1, 2, 3 and 4 weeks of continuous extension. The same specimen was used throughout the 4-week period and it was remounted on the extension stand aftet each measurement. Care was taken not to extend the chain over the chosen length of $21 \mathrm{~mm}$ or 25 $\mathrm{mm}$. The specimens were kept in air at room temperature throughout the test period.

Test 2 was performed in 4 subjects, who wore elastic chains between the upper or lower first molars and canines on both sides of the dental arch for 4 weeks. A Unitek elastic chain was worn on one side and an Ormco chain on the other side. The chains were worn only for the 


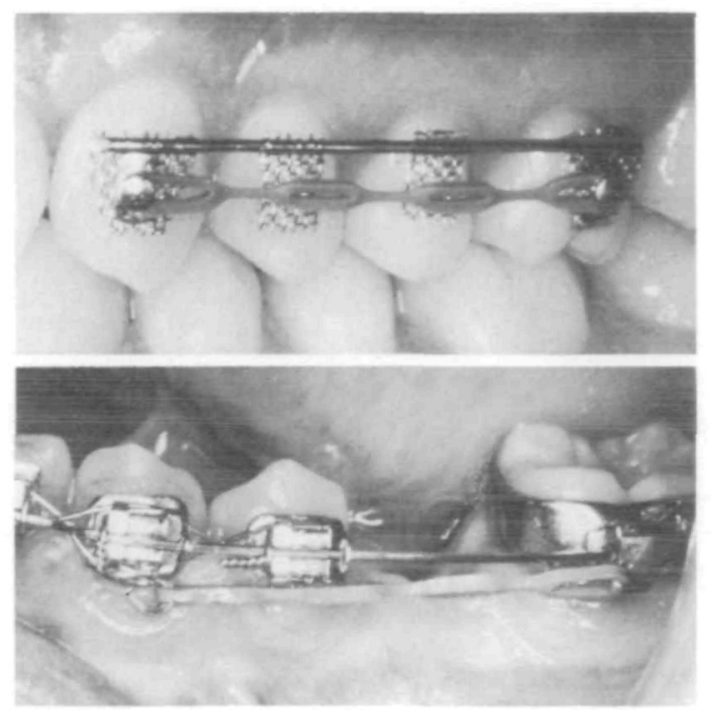

Figure 2 Appliance for the intra-oral application of an elastic chain.

purpose of the test. Hence, when necessary, an appliance was bonded to the teeth so that they would not move (Fig. 2). The extension of the chain was thus unchanged throughout the experiment. Ten specimens of each brand were tested. In 9 specimens, a chain of four rings (passive length for Unitek $11.6 \mathrm{~mm}$ and for Ormco $11.5 \mathrm{~mm}$ ) and in 1 specimen 3 rings were used (passive length for Unitek $8.3 \mathrm{~mm}$ and for Ormco $8.3 \mathrm{~mm}$ ). The chains were extended to an average length of $22.7 \mathrm{~mm}$ for the Unitek brand (201 per cent of the passive length) and to $22.3 \mathrm{~mm}$ for the Ormco brand (199 per cent of the passive length). The force exerted by the extended chain was measured at the start of test and then after 8 and 24 hours, 5 days and 1, 2, 3 and 4 weeks. After each measurement, the chain was inserted in the mouth again, taking care not to extend it over the intended length. To avoid the effect of relaxation with resultant increase in force, the chain was measured immediately after removal from the mouth.

Test 3 was performed in 25 subjects and was similar to test 2 except that the elastics were worn for 1 day. Unitek, as well as Ormco elastics comprised 4 specimens with 3 rings, 20 with 4 rings and 1 with 5 rings. Both brands of elastic were, on average, extended to 185 per cent of their original passive length.

Test 4 was performed in 20 subjects and was similar to tests 2 and 3 except that the force was measured at the start of the test and after 4 weeks. During the test period, the elastics were left untouched in the mouth and the teeth were not allowed to move. Three subjects wore chains of 3 rings in length, 16 subjects 4 rings and 1 subject wore a 5 ring chain. The average extension of the Unitek elastics was 188 per cent of their original passive length and of the Ormco elastics 191 per cent of their passive length.

\section{Statistical methods}

The results of tests 1 and 2 were analysed by regression analysis using the procedure GLM in the SAS programme package (SAS User's Guide: Statistics, 1982 Edition, SAS Institute Inc. Cary, N.C., USA). The force measured was studied with the factors brand (Unitek or Ormco), extension, time, the interaction between brand and extension and the initial force as covariable.

In tests 2, 3 and 4, the difference between the two brands was tested with a $t$-test. In tests 3 and 4 , the rank-correlation between extension, initial force and final force was calculated according to Spearman.

\section{Results}

\section{Test 1. Laboratory test}

As will be seen from Table 1, the development in time of the force values of the two brands of elastics was very similar during the laboratory test. There was an approximately exponential decline of the force so that after 4 weeks the elastics had lost about 30 per cent of their original force by an initial extension of 181 per cent ( $21 \mathrm{~mm}$ distance) and about 25 per cent after an initial extension of 215 per cent $(25 \mathrm{~mm}$ distance). The decline of the force value was greatest in the beginning of the test period, with a decline of 6-11 per cent during the first 15 minutes and 10-16 per cent during the first 2 hours.

\section{Test 2. Intra-oral use, periodic measurements during 4 weeks}

The decline of the force during intra-oral use of the elastics for 4 weeks is shown in Table 2 .

The decline of the force during intra-oral use of the elastic chains was much greater than in the laboratory tests. After 4 weeks, the force value was only 43 and 52 per cent of the original 
Table 1 Development of the force exerted by the elastics during a 4-week laboratory test $(n=10)$.

\begin{tabular}{|c|c|c|c|c|c|c|c|c|}
\hline \multirow[b]{4}{*}{ Time } & \multicolumn{4}{|c|}{$21 \mathrm{~mm}$} & \multicolumn{4}{|c|}{$25 \mathrm{~mm}$} \\
\hline & \multicolumn{2}{|c|}{ Unitek } & \multicolumn{2}{|c|}{ Ormco } & \multicolumn{2}{|c|}{ Unitek } & \multicolumn{2}{|c|}{ Ormco } \\
\hline & \multicolumn{2}{|c|}{ Extension $181 \%$} & \multicolumn{2}{|c|}{ Extension $183 \%$} & \multicolumn{2}{|c|}{ Extension $216 \%$} & \multicolumn{2}{|c|}{ Extension $217 \%$} \\
\hline & $\mathbf{g}$ & $\%$ & $\mathrm{~g}$ & $\%$ & $\mathrm{~g}$ & $\%$ & g & $\%$ \\
\hline Start & 301 & 100 & 286 & 100 & 352 & 100 & 351 & 100 \\
\hline $15 \mathrm{~min}$ & 275 & 92 & 270 & 94 & 312 & 89 & 322 & 92 \\
\hline 2 hours & 258 & 86 & 257 & 90 & 297 & 84 & 295 & 84 \\
\hline 8 hours & 246 & 82 & 244 & 85 & 276 & 78 & 290 & 83 \\
\hline 24 hours & 240 & 80 & 234 & 82 & 270 & 77 & 276 & 79 \\
\hline 3 days & 235 & 78 & 226 & 79 & 268 & 76 & 272 & 77 \\
\hline 1 week & 228 & 76 & 222 & 78 & 263 & 75 & 267 & 76 \\
\hline 2 weeks & 224 & 74 & 215 & 75 & 259 & 74 & 263 & 75 \\
\hline 3 weeks & 220 & 73 & 213 & 74 & 256 & 73 & 260 & 74 \\
\hline 4 weeks & 212 & 70 & 211 & 74 & 251 & 71 & 259 & 74 \\
\hline \multirow{2}{*}{$\begin{array}{l}\text { Average final } \\
\text { passive length mm } \\
\text { Per cent of original } \\
\text { passive length }\end{array}$} & \multicolumn{2}{|c|}{15.2} & \multicolumn{2}{|c|}{16.6} & \multicolumn{2}{|l|}{14.7} & \multicolumn{2}{|c|}{16.5} \\
\hline & \multicolumn{2}{|l|}{131} & \multicolumn{2}{|l|}{144} & \multicolumn{2}{|l|}{127} & \multicolumn{2}{|l|}{144} \\
\hline
\end{tabular}

Table 2 Development of the force exerted by the elastics during 4 weeks intra-oral use $(n=10)$.

\begin{tabular}{|c|c|c|c|c|}
\hline \multirow{3}{*}{ Time } & \multicolumn{2}{|c|}{ Unitek } & \multicolumn{2}{|c|}{ Ormco } \\
\hline & \multicolumn{2}{|c|}{ Average extension $201 \%$} & \multicolumn{2}{|c|}{ Average extension $199 \%$} \\
\hline & g & & $\mathrm{g}$ & $\%$ \\
\hline Start & 315 & 100 & 279 & 100 \\
\hline 8 hours & 207 & 66 & 202 & 72 \\
\hline 24 hours & 187 & 59 & 191 & 69 \\
\hline 5 days & 172 & 54 & 180 & 64 \\
\hline 1 week & 162 & 51 & 171 & 61 \\
\hline 2 weeks & 151 & 48 & 164 & 59 \\
\hline 3 weeks & 142 & 45 & 152 & 54 \\
\hline 4 weeks & 135 & 43 & 146 & 52 \\
\hline \multirow{2}{*}{$\begin{array}{l}\text { Average final } \\
\text { passive length mm } \\
\text { Per cent of original } \\
\text { passive length }\end{array}$} & \multicolumn{2}{|l|}{18.4} & \multicolumn{2}{|c|}{16.5} \\
\hline & \multicolumn{2}{|l|}{163} & \multicolumn{2}{|l|}{147} \\
\hline
\end{tabular}

value (Table 2). The decline was greatest in the initial phase after insertion; after 8 hours the force had declined by 28 and 34 per cent.

The regression analysis of the results of tests 1 and 2 revealed that the factors brand, extension, initial force and time had a significant influence on the force development during the test period. The interaction between brand and extension showed such an influence only in test 2. By far the most important factor was time. In comparison with the influence of time, the other factors were relatively unimportant.

$T$-test of the difference between the two brands in Test 2 showed that the average higher force exerted by the Unitek brand at the beginning of the test and the average higher force exerted by the Ormco brand at the end of the test period was significant $(0.001<\mathrm{P}<0.05)$. 
Table 3 Decline of force after 1 day of intra-oral use $(n=25)$.

\begin{tabular}{|c|c|c|c|c|c|c|c|c|c|c|c|c|}
\hline \multirow[b]{3}{*}{ Time } & \multicolumn{6}{|c|}{$\begin{array}{l}\text { Unitek } \\
\text { Average extension } 191 \text { per cent } \\
\text { range of extensions } 165-216 \text { per cent }\end{array}$} & \multicolumn{6}{|c|}{$\begin{array}{l}\text { Ormco } \\
\text { Average extension } 190 \text { per cent } \\
\text { range of extension } 148-226 \text { per cent }\end{array}$} \\
\hline & \multicolumn{3}{|c|}{ Force in grams } & \multicolumn{3}{|c|}{ Force in per cent } & \multicolumn{3}{|c|}{ Force in grams } & \multicolumn{3}{|c|}{ Force in per cent } \\
\hline & Mean & S.D. & Range & Mean & S.D. & Range & Mean & S.D. & Range & Mean & S.D. & Range \\
\hline Start & 299 & 34.9 & $230-370$ & 100 & & & 282 & 33.5 & $220-340$ & 100 & & \\
\hline 1 day & 179 & 34.5 & $120-260$ & 60 & 7.6 & $44-77$ & 183 & 20.8 & $150-230$ & 66 & 7.5 & $50-82$ \\
\hline
\end{tabular}

Table 4 Decline of force after 4 weeks of intra-oral use $(n=20)$.

\begin{tabular}{|c|c|c|c|c|c|c|c|c|c|c|c|c|}
\hline \multirow[b]{3}{*}{ Time } & \multicolumn{6}{|c|}{$\begin{array}{l}\text { Unitek } \\
\text { Average extension } 189 \text { per cent } \\
\text { range of extensions } 147-211 \text { per cent }\end{array}$} & \multicolumn{6}{|c|}{$\begin{array}{l}\text { Ormco } \\
\text { Average extension } 191 \text { per cent } \\
\text { range of extension } 148-213 \text { per cent }\end{array}$} \\
\hline & \multicolumn{3}{|c|}{ Force in grams } & \multicolumn{3}{|c|}{ Force in per cent } & \multicolumn{3}{|c|}{ Force in grams } & \multicolumn{3}{|c|}{ Force in per cent } \\
\hline & Mean & S.D. & Range & Mean & S.D. & Range & Mean & S.D. & Range & Mean & S.D. & Range \\
\hline Start & 312 & 39.6 & $230-370$ & 100 & & & 282 & 32.3 & $220-350$ & 100 & & \\
\hline 4 weeks & 147 & 29.6 & $110-220$ & 48 & 11 & $31-67$ & 145 & 24.9 & $100-200$ & 52 & 11.5 & $32-69$ \\
\hline
\end{tabular}

Test 3. Intra-oral use, measurements after I day, and Test 4. Intra-oral use, measurements after 4 weeks

The decline of the force recorded after 1 day's use of the elastics is in accordance with the findings of Test 2. After this time, the initial force decreased on average by 35 and 40 per cent (Table 3).

During the 4-week test period, both brands of elastics lost about 50 per cent of their force (Table 4). The results of test 4 are identical with those of test 2 for the Ormco elastics while the Unitek elastics were somewhat more stable in test 4 than in test 2 .

Neither in test 3 nor in test 4 was there a significant difference in force degradation between the two brands. In both tests there was a similar, large variation in the degree of force degradation between individual specimens for both brands. In no case, however, was the force measured less than $100 \mathrm{~g}$ after 4 weeks.

There were significant positive correlations in both tests between the degree of extension and both the initial force and the force after 1 day. However the degree of extension was negatively correlated to the force after 4 weeks. The coefficient of correlation was -0.23 for the Unitek chain and -0.31 for the Ormco chain. These correlations are not significant for the number of observations made. The mean force after 4 weeks for the Unitek chains extended less than the median extension was $148 \mathrm{~g}$, and for those extended more than the median value it was $138 \mathrm{~g}$. The corresponding values for the Ormco chains were $154 \mathrm{~g}$ (less extended) and $143 \mathrm{~g}$ (more extended).

\section{Discussion}

This study confirms the findings in previous investigations of a rapid decrease of the force developed by the elastic chains after the initial extension (insertion) and a subsequent force degradation at a slower rate (Andreasen and Bishara, 1970; Hershey and Reynolds, 1975; Wong 1976; Brantley et al., 1979; De Genova et al., 1985; Killinay and Duplessis, 1985). In our study, this behaviour of the chain was found both in the laboratory tests and in the intra-oral tests and was already evident during the first 
day. The force degradation was, however, more rapid and more extensive during intra-oral use than in the laboratory test. The results thus confirm those of Ash and Nikolai (1978). Our laboratory experiment was, however, restricted to testing in air.

The study was designed to simulate cuspid retraction after first premolar extraction with the aid of an elastic chain. The number of units (in most cases 4) in the chain corresponds to that used in clinical practice for canine retraction. The initial force of the chain extended to a distance of $21 \mathrm{~mm}$ (corresponding to the distance between the canine bracket and first molar hook) was around $300 \mathrm{~g}$. This force was measured with the chain in a dry state at room temperature, comparable to the actual situation during force control measurement upon insertion of an elastic chain in clinical practice. The chain was not prestretched. After 1 day of intra-oral use, the force was reduced to $60-70$ per cent of the initial value, i.e. to $180-190 \mathrm{~g}$. After the first day, there follows a slow reduction of the force exerted, to a level of 140-150 g after four weeks of intraoral use.

The initial high force level is of only short duration, probably much shorter than when, for example, an arch wire is deflected during ligation into a bracket. In the later case, the force exerted on the tooth may be much higher than the initial one measured in this study and also last much longer (until the tooth has moved). The initial high force necessary for the insertion of an elastic chain should therefore not be a serious disadvantage.

The optimal force level for the bodily retraction of an upper canine was stated by Reitan (1957) to be $150-250 \mathrm{~g}$ and that for a lower canine to be $100-200 \mathrm{~g}$. In a recent critical review of force magnitude based on clinical studies of canine retraction, Quinn and Yoshikawa (1985) estimated the maximally efficient canine retraction force to be between 100 and $200 \mathrm{~g}$. An elastic chain of the length and type used in this study is capable of exerting a force of this magnitude for the time period usually chosen as the control interval. During actual use, however, the length of the chain will decrease due to the movement of the tooth. The rate of tooth movement may be estimated to be around $1 \mathrm{~mm}$ per four-week period (Hixon et al., 1969; Paulson et al., 1970; Huffmann and Way, 1983). This will perhaps decrease the force to a sub-optimal level. When using an elastic chain of the type tested in this investigation, it therefore seems advisable to use a force above $300 \mathrm{~g}$ upon insertion of the chain for the retraction of a canine.

Judging from the results of test 4 , it is, not certain that a large extension of the chain with a resulting high initial force will guarantee high force after 4 weeks. There is probably a risk of a larger permanent set during the period of clinical use when the chains are greatly extended at the time of insertion.

An additional factor to be considered in connection with a sliding movement of a tooth along an arch wire is the force necessary to overcome friction between the bracket and the wire. The magnitude of the force that dissipates through friction is unknown. It is assumed that in practice the friction will be largely eliminated by muscular pressure and forces of mastication. In any event, Huffmann and Way (1983) found no difference in the efficiency of sliding a tooth, using the same force, along arch wires of different sizes.

\section{Address for correspondence}

Dr. R. Kuster

Klinik für Kieferorthopädie

Freiburgstrasse 7

CH-3010 Berne

Switzerland

\section{References}

Andreasen G F, Bishara S E 1970 Comparison of alastic chains with elastics involved with intra-arch molar to molar forces. Angle Orthodontist 40: 151-158

Ash J L, Nikolai R J 1978 Relaxation of orthodontic elastomeric chains and modules in vitro and in vivo. Journal of Dental Research 57: 685-690

Bishara S E, Andreasen G F 1970 A comparison of time related forces between plastic alastics and latex elastics. Angle Orthodontist 40: 319-328

Brantley W A, Salander S, Myers C L, Winders R V 1979 Effects of prestretching on force degradation characteristics of plastic modules. Angle Orthodontist 49: 37-43

De Genova D C, Mclnnes-Ledoux P, Weinberg R, Shaye R 1985 Force degradation of orthodontic elastomeric chains-A product comparison study. American Journal of Orthodontics 87: 377-384

Hershey H G, Reynolds W G 1975 The plastic module as an orthodontic tooth moving mechanism. American Journal of Orthodontics 67: 554-562

Hixon E H, Atikian H, Callow G E, McDonald H W, Tacy R J 1969 Optimal force, differential force and anchorage. American Journal of Orthodontics 55: 437-457 
Hofmann T, Miethke R-R 1981 Das Kräfteverhalten elasticher Ligaturen. Fortschritte der Kieferorthopädie 42: 296-304

Howard R S, Nikolai R J 1979 On the relaxation of orthodontic elastic threads. Angle Orthodontist 49: 167172

Huffmann D J, Way D C 1983 A clinical evaluation of tooth movement along arch wires of two different sizes. American Journal of Orthodontics 83: 453-459

Killinay D M, Duplessis J 1985 Relaxation of elastomeric chains. Journal of Clinical Orthodontics 19: 592-593

Kovatch J S, Lautenschlager E P, Apfel D A, Heller J C 1976 Load-extension-time behaviour of orthodontic alastics. Joumal of Dental Research 55: 783-786

Paulson R C, Speidel T M, Isaacson R J 1970 A laminagraphic study of cuspid retraction versus molar anchorage loss. Angle Orthodontist 40: 20-27
Persson M, Kiliaridis S, Lennartsson B 1983 Comparative studies on orthodontic elastic threads. European Journal of Orthodontics 5: 157-166

Quinn R S, Yoshikawa D K 1985 A reassessment of force magnitude in orthodontics. American Journal of Orthodontics 88: 252-260

Reitan K 1957 Some factors determining the evaluation of forces in orthodontics. American Journal of Orthodontics 43: $32-45$

Wong A K 1976 Orthodontic elastic materials. Angle Orthodontist 46: 196-205

Young J, Sandrik J L 1979 The influence of preloading on stress relaxation of orthodontic elastic polymers. Angle Orthodontist 49: 104-109 